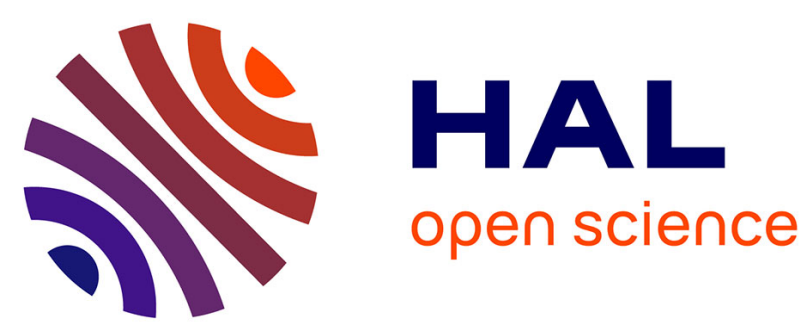

\title{
The virtual food system: Innovative models and experiential feedback in technologies for winemaking, the cereals chain, food packaging and eco-designed starter production
}

Cesar Arturo Aceves-Lara, Violaine Athès, Patrice Buche, Guy Della Valle, Vincent Farines, Fernanda Fonseca, Valérie Guillard, Kamal Kansou, Magdalena Kristiawan, Vincent Monclus, et al.

\section{- To cite this version:}

Cesar Arturo Aceves-Lara, Violaine Athès, Patrice Buche, Guy Della Valle, Vincent Farines, et al.. The virtual food system: Innovative models and experiential feedback in technologies for winemaking, the cereals chain, food packaging and eco-designed starter production. Innovative Food Science \& Emerging Technologies / Innovative Food Science and Emerging Technologies, 2018, Food Science and Technology in France: INRA's contribution to this area, 46, pp.54-64. 10.1016/j.ifset.2017.10.006 . lirmm-01651998

\section{HAL Id: lirmm-01651998 \\ https://hal-lirmm.ccsd.cnrs.fr/lirmm-01651998}

Submitted on 29 Nov 2017

HAL is a multi-disciplinary open access archive for the deposit and dissemination of scientific research documents, whether they are published or not. The documents may come from teaching and research institutions in France or abroad, or from public or private research centers.
L'archive ouverte pluridisciplinaire HAL, est destinée au dépôt et à la diffusion de documents scientifiques de niveau recherche, publiés ou non, émanant des établissements d'enseignement et de recherche français ou étrangers, des laboratoires publics ou privés. 


\title{
The virtual food system: Innovative models and experiential feedback in technologies for winemaking, the cereals chain, food packaging and eco- designed starter production
}

\author{
César Arturo Aceves Lara ${ }^{\mathrm{e}}$, Violaine Athès ${ }^{\mathrm{b}}$, Patrice Buche ${ }^{\mathrm{d}}$, Guy Della Valle ${ }^{\mathrm{a}, *}$, Vincent Farines ${ }^{\mathrm{h}}$, \\ Fernanda Fonseca $^{\mathrm{b}}$, Valérie Guillard ${ }^{\mathrm{d}, *}$, Kamal Kansou ${ }^{\mathrm{a}}$, Magdalena Kristiawan ${ }^{\mathrm{a}}$, \\ Vincent Monclus ${ }^{\mathrm{b}}$, Jean-Roch Mouret ${ }^{\mathrm{g}, *}$, Amadou Ndiaye ${ }^{\mathrm{c}}$, Pascal Neveu ${ }^{\mathrm{f}}$, Stéphanie Passot ${ }^{\mathrm{b}}$, \\ Caroline Pénicaud $^{\mathrm{b}, *}$, Jean-Marie Sablayrolles ${ }^{\mathrm{g}}$, Jean-Michel Salmon ${ }^{\mathrm{h}}$, Rallou Thomopoulos ${ }^{\mathrm{d}, *}$, \\ Ioan Cristian Trelea ${ }^{\mathrm{b}}$
}

a BIA, UR1268, INRA, 44316 Nantes, France

b GMPA, UMR782 AgroParisTech, INRA, Université Paris-Saclay, 78850 Thiverval-Grignon, France

c I2M, USC1368, INRA, 33405 Talence, France

d IATE, UMR1208, CIRAD, INRA, Montpellier SupAgro, Université de Montpellier, 34060 Montpellier, France

e LISBP, UMR792, INRA, 31400 Toulouse, France

${ }^{\mathrm{f}}$ MISTEA, UMR729, INRA, Montpellier SupAgro, 34060 Montpellier, France

g SPO, INRA, UMR1083, INRA, SupAgro, Université de Montpellier 1, 34060 Montpellier, France

h Pech Rouge, UE0999, INRA, 11430 Gruissan, France

\section{A R T I C L E I N F O}

\section{Keywords:}

Modeling

Information system

Knowledge

Ontology

Eco-design

Optimization

Decision support

Qualitative

Parameter

Sensor

\begin{abstract}
A B S T R A C T
This article presents an overview of five use-cases that illustrate food-system modeling approaches, most of them combining quantitative and qualitative methods. The cases deal with issues as diverse as: the modeling of winemaking fermentation; the choice of a food packaging material; the design of solid foam cereal products; argumentation modeling to support multistakeholder decision-making, and the control of freeze-drying for ecodesign purposes. They tackle several challenges to modeling and knowledge engineering in food systems: capitalizing data and knowledge; structuring a shared vocabulary and domain knowledge in an ontology; formalizing viewpoints and contradictions from food-related debates; supporting multi-criteria decision-making.
\end{abstract}

\section{Introduction}

This article aims to demonstrate how abstraction-as tackled by mathematical as well as computer science approaches (e.g. knowledge representation, decision support, etc.)—can prove highly beneficial for dealing with issues as concrete as those found in food technologies. Indeed, food processes are complex for various reasons, some of which are recalled here:

- numerous criteria are used to describe food properties;

- numerous food-process parameters of impact food properties;

- these parameters are non-independent, and can be quantitative or qualitative;

- they are difficult to measure online due to sensors limitations;

- they can be very complicated to mathematically model because their dynamics are usually nonlinear and they are over-parameterized (quantitative case);

- parameter values are consequently often ill-known, missing, imprecise or uncertain.

These scientific barriers make food processes a challenge for modeling or data engineering approaches.

Five successful attempts are presented in this paper, most of them combining quantitative and qualitative approaches. They deal,

\footnotetext{
* Corresponding authors.

E-mail addresses: guy.della-valle@inra.fr (G. Della Valle), guillard@univ-montp2.fr (V. Guillard), jean-roch.mouret@inra.fr (J.-R. Mouret), caroline.penicaud@inra.fr (C. Pénicaud), rallou.thomopoulos@inra.fr (R. Thomopoulos).
} 
respectively, with the modeling of winemaking fermentation to control wine characteristics (Section 2), the design and choice of a packaging material for a given food product (Section 3), the design of solid foam cereal products (Section 4), argumentation models to support decisionmaking among multiple food-chain stakeholders (Section 5), and the control of freeze-drying for both reduction of energy efficiency and bacterial quality objectives (Section 6). The last two sections feature specificities in the type of approach, as Section 5 proposes a purely qualitative approach whereas Section 6 presents a systemic approach with eco-design purposes.

These studies illustrate how to:

- capitalize data and knowledge (Section 2, 3 and 4);

- structure a shared vocabulary and domain knowledge in an ontology (Section 2 and 6);

- formalize viewpoints and contradictions in a debate (Section 5);

- support multi-criteria decision-making (Sections 3, 5 and 6).

Focused on models and experience developed within the "Science for Food and Bioproduct Engineering" (CEPIA) Division of the French INRA research institute, the typology of problems covered by the experiences presented in the paper is illustrative of the type of issues that one can face in the food industry. Launched by the CEPIA Division, a similar initiative at the European level is currently pursued in the COST Action "FoodMC" (www.inra.fr/foodmc).

In winemaking (Section 2), the most important fermentative aromas were successfully described using mathematical modeling. In these processes, several state variables were estimated online thanks to sensors developed at the INRA. Moreover, an integrated methodology was proposed for process control coupling models from online sensors, databases and ontologies.

In the field of food packaging (Section 3), mathematical models were used to describe the evolution of atmosphere inside the packaging headspace based on packaging and food characteristics. These models are used to study food transformation and to help improve packaging design. Packaging improvements were obtained by coupling models with multicriteria optimization.

Qualitative models can be seen as a flexible alternative when there is insufficient information to develop a mathematical model. These kinds of models integrate available scientific knowledge and experts' know-how in process description. Here, knowledge-based models were used through qualitative reasoning and phenomenological modeling for the design of solid foam cereal products (Section 4), where they enabled prediction and learning of cereal food texture and rheology.

That said, food technologies are not limited to process modeling. Food systems involve various stakeholders, each with their own objectives, priorities, interests, etc. Qualitative models, in particular computer science approaches, offer a relevant approach to represent stakeholders' knowledge and their logics behind their reasoning. This paper develops an example presenting an argumentation approach to express a debate concerning breadmaking recommendations and support decisionmaking (Section 5).

Finally, we present an eco-design approach applied for the production of stabilized lactic acid bacteria (Section 6). Life-cycle assessment (LCA) was used to quantify the system's global environmental impacts, providing opportunities for system eco-design and innovation. At unit operation level, bacterial quality and energy consumptions were simulated during freeze-drying, allowing eco-reasoned process control. Knowledge formalization in an ontology served to move towards a multicriteria analysis combining process conditions, product quality and environmental impact at both unit-operation and whole-system level.

As a synthesis, we propose a summary of the issues, methods and results presented in the paper, before concluding with feedback in the form of a global table.

\section{Winemaking fermentation: from online monitoring to modeling} and information system for data sharing

Alcoholic fermentation, a key step of the winemaking process, is likely to change considerably in the future. Indeed, winemakers increasingly recognize the need for tools controlling fermentation according to the type of wine desired and the characteristics of the grape must. The main objective is to control the bioconversion of sugar into ethanol and $\mathrm{CO}_{2}$, but the ability to directly control wine characteristics would be a major step forward. Even though wine quality is notoriously difficult to predict (Francis \& Newton, 2005; Swiegers, Bartowsky, Henschke, \& Pretorius, 2005), some "quality marker molecules" have been identified. Among these markers, fermentative aromas-generated by yeast secondary metabolism - are the most abundant and help shape the fruity flavor.

To tackle these challenges, we developed innovative systems for online monitoring of the kinetics of (i) the alcoholic fermentation and (ii) the major fermentative aromas. The monitoring of alcoholic fermentation is based on measuring $\mathrm{CO}_{2}$ release. In parallel, we developed an online GC (gas chromatography) system to monitor the synthesis of the main higher alcohols and esters (Morakul et al., 2011; Mouret, Morakul, Nicolle, Athes, \& Sablayrolles, 2012). These online monitoring devices allow precise determination of the chronology of synthesis of some key compounds in alcoholic fermentation. The high acquisition frequency makes it possible to calculate the kinetic parameters of synthesis of these molecules, i.e. instantaneous production rate and production yields. These kinetic data are of primary importance for a better understanding of yeast metabolism, but they also have practical interest-instantaneous $\mathrm{CO}_{2}$ production rate, for instance, is directly proportional to the energy required for temperature control in fermentation tanks (Colombie, Malherbe, \& Sablayrolles, 2007; Goelzer, Charnomordic, Colombié, Fromion, \& Sablayrolles, 2009). The online data collected were used to build a model predicting the fermentation kinetics (Malherbe, Fromion, Hilgert, \& Sablayrolles, 2004), gas-liquid ratio (Morakul et al., 2011) and production kinetics of five fermentative aromas (Mouret, Farines, Sablayrolles, \& Trelea, 2015). These data were also used to implement an information system called ALFIS (alcoholic fermentation information system) that allows the acquisition, annotation and consultation of online and offline measurements and provides a rich digital resource for sharing data across technologies and disciplines.

Using 125 fermentations corresponding to 49 natural and synthetic musts and 20 strains, we built a dynamic model—consisting of ordinary differential equations - to predict the main reaction of the fermentation (Malherbe et al., 2004). This model (called MOMAF, for "modeling of the main reaction of alcoholic fermentation") predicts cell growth, fermentation rate and sugar consumption (proportional to ethanol and $\mathrm{CO}_{2}$ production) from two main fermentation parameters: temperature (including non-isothermal profiles, which are widely used in the industry) and nitrogen additions. This explanatory model is based on physiological considerations and takes into account the main phenomena directly affecting kinetics in enological conditions, including the effects of: (i) nitrogen in yeast synthesis (growth phase) and activation of metabolism (stationary phase); (ii) the transport of sugar into yeast cells; (iii) ethanol inhibition; and (iv) temperature. The results obtained were very satisfactory: mean error between experimental and simulated data was lower than 5\% (Malherbe et al., 2004). MOMAF was licensed to a private company and is currently marketed as a simulation software. The model was then completed with a thermal model (Colombie et al., 2007) evaluating the power required to cool the tank during the winemaking process (as fermentation is a very exothermic process). This model opens up new perspectives for the control of alcoholic fermentation, for example to optimize the fermentation duration, tanks scheduling, energy consumption peaks and total energy required.

The next challenge in the modeling of enological fermentation was 


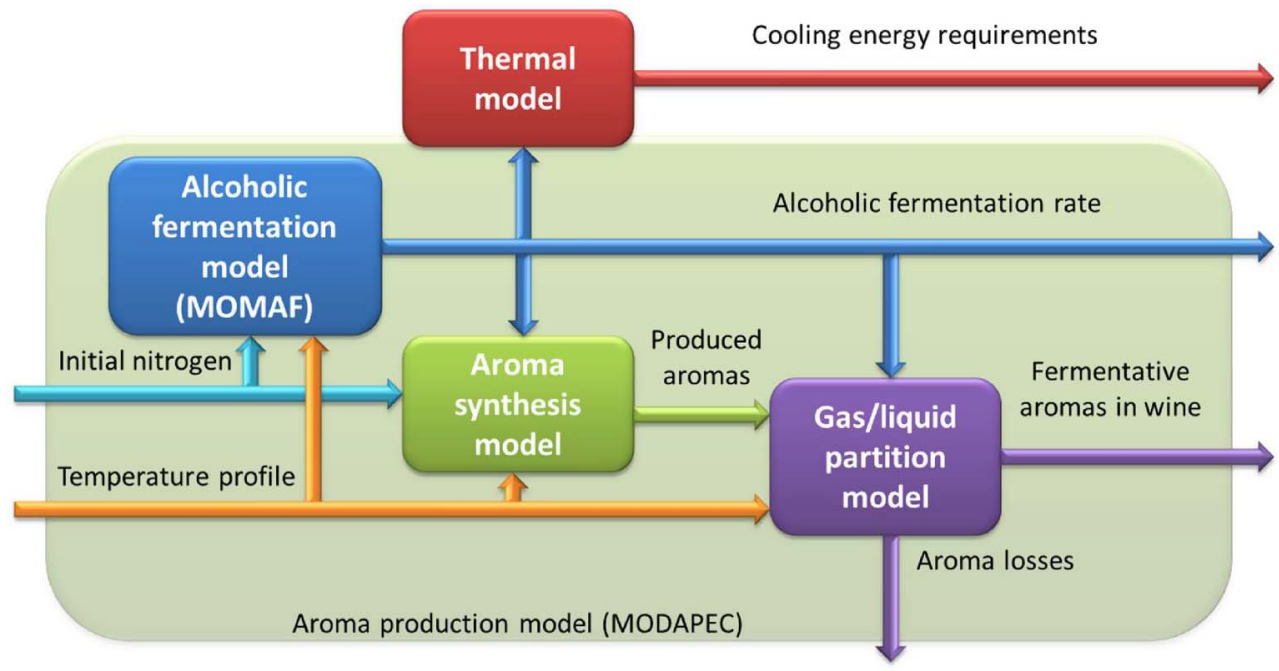

Fig. 1. Structure of the global wine fermentation model.

to consider the kinetics of production of fermentative aromas. Online data were acquired in the gas phase. The first step was therefore to model the gas-liquid ratio $\left(\mathrm{k}_{\mathrm{i}}\right)$ of these volatiles throughout the fermentation process to calculate their liquid concentrations. The model obtained was very accurate and made it possible to calculate, for the first time, the losses of volatiles in the gas phase. For esters, up to $70 \%$ of the volatile compounds produced were lost at high temperature $\left(30{ }^{\circ} \mathrm{C}\right)$. The difference between observed losses and losses estimated from predicted $\mathrm{k}_{\mathrm{i}}$ values never exceeded $3 \%$. Finally, using this model, we calculated the total production of fermentative aromas-corresponding to the sum of liquid accumulation and gas losses (Morakul et al., 2011). Based on fermentations performed at different temperatures and initial nitrogen concentrations, we modeled the impact of these two fermentation parameters on the production yields of five fermentative aromas representative of the different chemical families. We then integrated these yields into the MOMAF model (Malherbe et al., 2004) to obtain a dynamic model predicting the production kinetics of these five volatile compounds throughout alcoholic fermentation (called MODAPEC, for "modeling of aroma production in enological conditions"), as shown in Fig. 1 (Mouret et al., 2015). Predictions were very accurate, as the mean difference between experimental and estimated values for fermentative aroma synthesis throughout the process was below $10 \%$. This is the first model to simulate the production kinetics of fermentative aromas, and opens up fresh prospects for the development of innovative strategies to control the production of these aromas in winemaking. Compromises between optimization of the main reaction and aroma production will be necessary. For example, performing the fermentation at low temperature limits the loss of esters but increases the fermentation time. It will therefore be necessary to find a compromise in temperature management to get high aroma concentrations in the final wine after acceptable fermentation durations.

Online data were also used to build a winemaking fermentation knowledge management system (ALFIS). The objective was to manage a large amount of data to organize it and extract key knowledge. The information system combined the acquisition of (i) online data from 52 fermenters (36 at lab scale and 16 at pilot scale), (ii) offline data from biological analyses (such as cell number or concentration of extracellular metabolites) and (iii) metadata (expert opinions, operation descriptions, faults, etc.). These data and metadata were formalized in XML and RDF (Neveu et al., 2012). Based on controlled vocabulary, the model provides flexibility and a generic method for managing heterogeneous, multisource data. Data are available through a Web interface. The database contains the measurements from 7090 fermentations. Ontologies were used to classify the data obtained and improve the organization of these knowledge-sets. For example, a specific ontology of events (faults or enological operations) is used to automatically identify wrong online measurements, which clearly improved the understanding and sharing of quality data. Indeed, by mobilizing a machine-understandable controlled vocabulary (such as sampling or cappunching), this ontology enables to automatically avoid misinterpretation of fermentation data (Neveu et al., 2012).

Moreover, to integrate data sources ahead of further analysis to answer complex questions that require access to various scientific agrifood data sources, we developed the Agri-Food Experiment Ontology (AFEO), a new ontology resource merging two existing ontology resources, i.e. OAE (Ontology for Agriculture Experiment) and OFPE (Ontology for Food Processing Experiment), as generic knowledge representations of two respective sub-domains, i.e., agricultural practices and food transformation processes. The AFEO and its specialization contain 136 concepts that cover various agricultural activities and entities, food products and operations, and representative attributes in viticulture and winemaking experiments (Muljarto, Salmon, Neveu, Charnomordic, \& Buche, 2014). Fig. 2 represents a part of the whole ontology, containing different viticulture entity and activity classes, winemaking-specific product and operation classes, and their semantic relations.

\section{Decision support tools in the field of food packaging: design and/or choice of a packaging material for a given food product}

Choice of packaging material is not trivial for food manufacturers, especially when specific packaging functionalities are sought. For example, a narrow range of gas or vapor permeabilities is targeted for the packaging to maintain optimal food quality during storage and thus prolong food-product shelf-life (Angellier-Coussy, Guillard, Guillaume, \& Gontard, 2013). In the case of Modified Atmosphere Packaging (MAP) technology for respiring products such as fresh fruit and vegetables, the gas $\left(\mathrm{O}_{2} / \mathrm{CO}_{2}\right)$ permeabilities of the packaging material need to match the respiration properties of the product (Floros \& Matsos, 2005; Guillaume, Guillard, \& Gontard, 2010). Respiration is an intrinsic food property that differs in rate from one product to another, making it impossible to generalize the use of one packaging film formulation for every single variety of fruit and vegetables. To avoid having to repeat numerous experimental tests to fit packaging to product, a virtual MAP modeling tool called 'Tailorpack' was proposed. Tailorpack computes the evolution of atmosphere inside the packaging headspace using packaging and food characteristics as input parameters (Cagnon, Méry, Chalier, Guillaume, \& Gontard, 2013; Guillard, Guillaume, \& Destercke, 2012). When packaging 


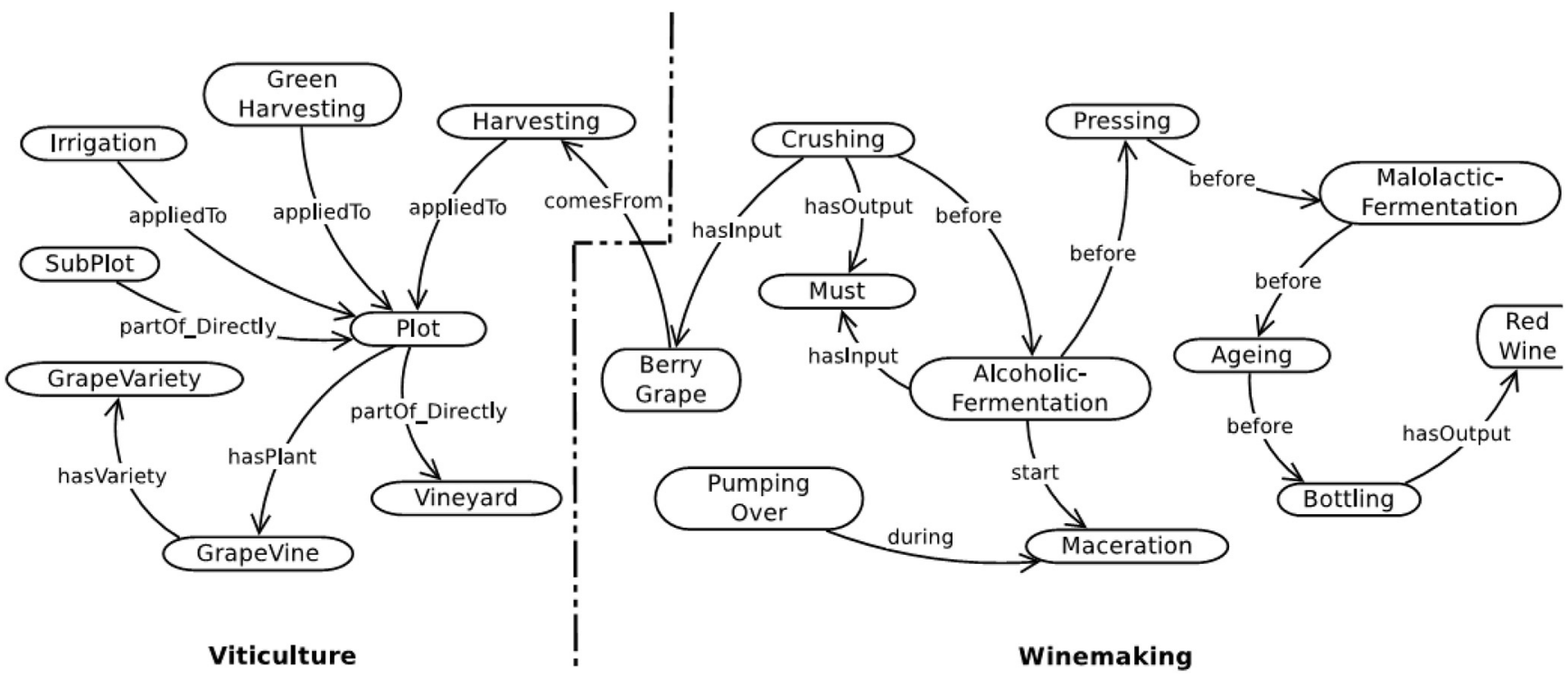

Fig. 2. A part of the AFEO that represents viticulture and winemaking integration.

characteristics are unknown, the same model can be used in a reverse manner to identify the window of gas permeabilities suitable for obtaining and maintaining optimal in-pack storage atmosphere conditions at equilibrium. This type of modeling tool empowers all food-chain stakeholders with a more rational approach to packaging design instead of the prevailing empirical "pack-and-pray" approach.

Quite often, the choice of a packaging material for a given application revolves around more than just its permeability characteristics, to encompass a combination of several criteria-criteria including, in addition to permeabilities, the cost of the raw material, its machinability, its sealability, its environmental impact, etc. The choice of a packaging material is thus the answer of multi-criteria querying addressed to a collection of packaging solutions, etc. In order to take into account this aspect, a decision support system (EcoBioCAP DSS) was developed to help users take the right decision in the field of food packaging (Guillard et al., 2015; Tamani et al., 2015). What follows is a demonstration of how such tools, at the junction between different fields of expertise such as food engineering, computer science, knowledge engineering, and so on, have been developed.

\subsection{From food engineering modeling tools ...}

The first step in the building of decision-support tools (DST) in the field of food packaging is to develop the numerical program that will serve to compute the evolution of mass transfer and quality in the food/ packaging system. The decay of fresh products is always related to mass transfer phenomena occurring through the packaging material and within the food (e.g. $\mathrm{O}_{2}$ permeation and diffusion) that trigger degradation-driven spoilage reactions in the food (e.g. oxidation, respiration, aerobe growth). Mastering mass transfer in the food/packaging system enables to control and limit the food degradation, which is why such mass transfer properties are such important product process specifications (Angellier-Coussy et al., 2013; Chaix, Broyart, et al., 2015). Several mathematical models were developed combining mass transfer models (based on Fick's laws) with models of food degradation-Mickaëlis-Menten equation for respiration or first-order reactions for oxidation for instance-(Bacigalupi, Lemaistre, Peyron, Guillard, \& Chalier, 2013; Pénicaud, Broyart, Peyron, Gontard, \& Guillard, 2011). In addition to the aforementioned Tailorpack application developed for fruit and vegetables, we developed the Map'Opt application for non-respiring products that can predict microbial growth as a function of packaging permeabilities and initial gas concentrations initially flushed in headspace at the time of packaging (Chaix, Couvert, Guillaume, Gontard, \& Guillard, 2015; Guillard, Couvert, et al., 2016). The Map'Opt application is used to adjust the packaging material to "the strict minimum", i.e. just those necessary mass transfer properties necessary to maintain the protective atmosphere in a given range of values. This approach is an alternative to that currently used in industry for MAP of non-respiring products, which is based on the by-default use of high-barrier films to be sure of maintaining the protective atmosphere throughout the product's shelf life. These high-barrier films are not only expensive but also generally multilayers that are currently not recycled, which raises environmental concerns for the food chain as a whole.

\section{2. ... towards multi-criteria tools}

Mathematical models for food engineering do allow some technical outputs to be computed but are not sufficient for decisionmaking in an industrial world where choice of a packaging material is a multi-criteria decision. To take into account this aspect, the EcoBioCAP tool was developed to choose the most suitable packaging material for respiring produce from in a dedicated database by answering multi-criteria querying (currently four criteria considered in the first prototype) (Guillard et al., 2015). This tool is able to answer the kind of query that reads: "I want a packaging material that will maintain the quality of strawberries (i.e. with the permeability properties that match the respiration of strawberries), at a cost of less than $€ 3$ per $\mathrm{kg}$, and if possible transparent and derived from renewable resources". Flexible querying methodologies employed in knowledge engineering were used to develop these tools (Buche, Destercke, Guillard, Haemmerlé, \& Thomopoulos, 2012; Destercke, Buche, \& Guillard, 2011). EcoBioCAP retrieves respiration characteristics from the product database and uses this data plus other user-entered characteristics such as pack geometry to compute the optimal permeabilities for the product. These permeabilities are automatically considered as mandatory preferences associated to selection criteria for the query, to which are added other mandatory or optional preferences that are determined by the user. The flexible querying modulus polls the packaging database to retrieve the material that best satisfies the query preferences, and proposes as output a ranking of these materials. The DST can manage imprecise data and missing data (Destercke et al., 2011). An answer is guaranteed even if no material satisfies the mandatory criteria. This type of tool marks a significant breakthrough, as it had never before been attempted in the field of food packaging. The food chain increasingly needs such DST to help address its food security and food safety issues and reduce its global 
environmental impact.

\subsection{On the importance of data warehouses in decision-making}

To propose DSTs that are efficient, i.e. that provide a real decision variable and not just technical outputs (e.g. values of mass flux, packaging properties, etc.) which are insufficient for addressing realworld decisions, it is necessary to couple mathematical models with coherent and consistent data warehouses containing all the characteristics required for running simulations and addressing decisions. In the special case of EcoBioCAP \& Map'Opt tools, all the data required for running simulations (food characteristics, bacterial growth parameters and packaging permeabilities) are structured and stored in a dedicated data warehouse according to a unique and specific ontology dedicated to the food, bacteria and packaging fields (Buche, Dervaux, et al., 2013; Buche, Dibie, Ibanescu, and Soler, 2013). Having this purpose-dedicated data structure available makes it easy to re-use the data in various simulation programs such as the virtual MAP modeling tools Map'Opt and EcoBioCAP. The ontology dedicated to mass transfer counts 52 relation concepts defining types of measurement, e.g. permeabilities and diffusivities, described by 62 quantities associated with 189 units of measure including conversion factors and 998 symbolic concepts representing objects of study, e.g. food matrices, packaging, with the associated annotated data ( $>2000$ experimental measures) all available on the @Web platform at http://www6.inra.fr/cati-icat-atweb/ Ontologies/Transmat. A description of the data warehouse can also be found in Guillard, Buche, et al., 2016.

\section{Basic knowledge-based models for the design of solid foam cereal products}

Solid cereal foods can be considered as solid foams, which are generally obtained through processes such as breadmaking or extrusion cooking. These processes mainly generate a succession of two transformations: (1) the transition from a divided solid medium (the flour) into a deformable continuous one (the flour dough or the starchy melt); and (2) the creation of a porous, cellular, ductile or fragile structure, either by direct expansion or by fermentation (Fig. 3). For both phenomena, knowledge of rheological properties is essential, although still incomplete, and generating it is a challenge. This is one of the main reasons why, despite the large amount of work dedicated to cereal processing, there is still no deterministic model, based on continuum mechanics, that can satisfactorily simulate these two phenomena, and $a$ fortiori support the design of innovative cereal products. In industry, product design is mainly achieved through trial-and-error approaches, often relying on experts' know-how, or at best, through data-based modeling

To better integrate scientific knowledge in the design of cereal foods, flexible models (i.e. simple to use, easy to update, re-using model fragments, and not too costly in terms of parameterization) could be used to run simulations for diverse parameters and scenarios. Being based on scientific knowledge, the model structure can be adapted to a wide range of processes and products. When scientific knowledge does not cover a full process, technological (or expert) knowledge can generally fill the gap. This kind of model should thus combine core scientific understanding of material changes as reflected in variations of rheological properties-which is why they are called Basic Knowledge Models (BKM) (Della Valle et al., 2014). Here we present our recent advances in BKMs applied to solid cereal food processes, e.g. extrusion and breadmaking.

Mixing is the first step in both processes. It homogenizes the ingredients in order to obtain, thanks to mechanical input, a deformable medium. This operation is complex, because both dough and melt are non-Newtonian, viscoelastic and strain-history-dependent fluids, which is still a challenging area for modeling. The use of numerical models would therefore require huge developments to take these features into account. However, to get a fair control of this operation, it is first necessary to determine the Specific Mechanical Energy (SME) delivered to the material (Fig. 3). SME governs this transition as it reflects starch destructuring (melting and depolymerization during extrusion) (Barron, Della Valle, Colonna, \& Vergnes, 2002) as well as, to a lesser extent, gluten network structuration in the dough (Shehzad, Chiron, Della Valle, Lamrini, \& Lourdin, 2012). It is linked to viscous dissipation, such that as a first approximation, one can write:

$S M E / t_{m}=\eta \cdot \dot{\gamma}^{2}$

where $t_{m}$ is mixing time, $\dot{\gamma}$ is shear rate and $\eta$ is shear viscosity, as expressed in Table 1 . In the case of a continuous reactor like extrusion, $t_{m}$ is unknown, so Eq. (1) is replaced by the integration of its local expression over the total melt volume $V$ :

$S M E=1 /\left(\rho_{m} \cdot Q_{v}\right) \cdot \int_{V} \eta \dot{\gamma}^{2} d V$

where $Q_{v}$ is volume flow rate and $\rho_{m}$ is melt density. In the case of starchy-product extrusion, $S M E$ can be computed through the combinations of various equations similar to Eq. (2), performed by the software Ludovic $^{\circledast}$ (Della Valle, Barrès, Plewa, Tayeb, \& Vergnes, 1993). It is thus possible to compute $S M E$ variations with extrusion parameters and, hence, to induce the structural changes of starch.

$K$ is the flow consistency index, $m$ and $n$ are flow behavior index in the power law and the cross-model, respectively, $M C$ is moisture content, $T$ is temperature, $T_{g}$ is glass transition temperature, $\dot{\varepsilon}$ is biaxial

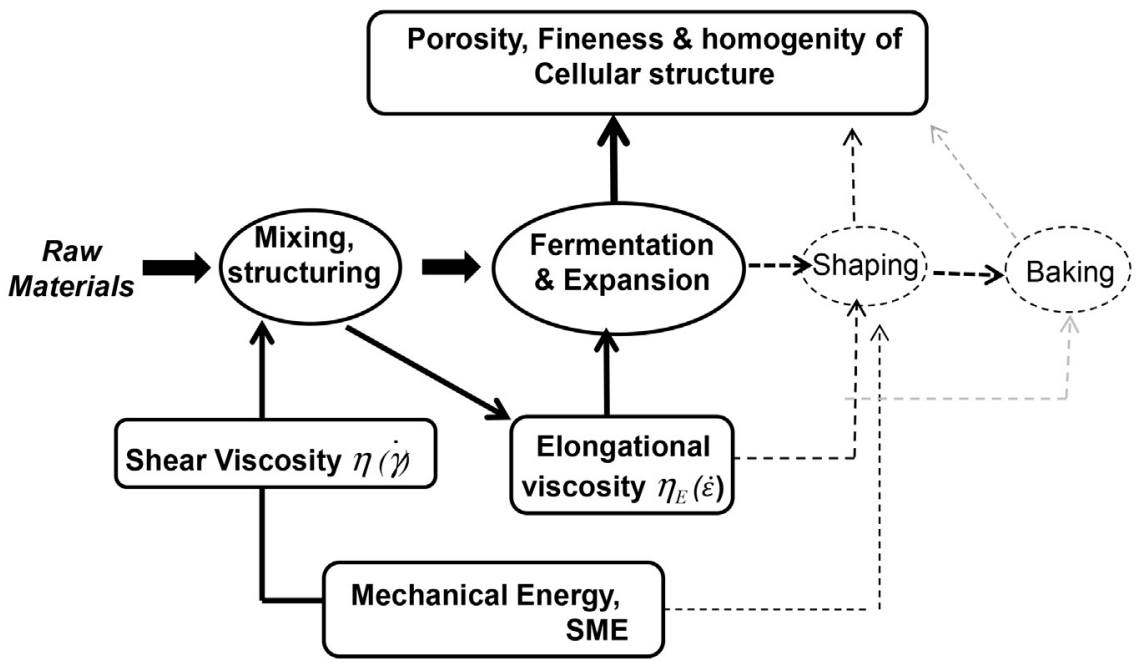

Fig. 3. Conceptual scheme of cereal solid foams and the significant influence of rheological properties on their cellular structure. Dotted lines flag possible complementary operations, which have less significant impact on cellular structure. (adapted from Della Valle et al., 2014) 
Table 1

Main rheological models for shear and elongational viscosities of cereal products. (from Kristiawan, Chaunier, Della Valle, Ndiaye, \& Vergnes, 2016, and Turbin-Orger, Shehzad, Chaunier, Chiron, \& Della Valle, 2016)

\begin{tabular}{lll}
\hline $\begin{array}{l}\text { Process \& material } \\
\text { strain mode }\end{array}$ & Extrusion of starchy melts & Breadmaking \\
\hline Shear & Power law $\eta=K \cdot \dot{\gamma}^{m-1}$ & Cross-model $\eta=\frac{\eta_{0}}{1+\left(\dot{\gamma} / \dot{\gamma}_{0}\right)^{n}}$ \\
Elongation & Elongational viscosity & Stress \\
& $\eta_{E} \approx$ storage modulus $E^{\prime}$ & $\tau=\eta_{E} \cdot \dot{\varepsilon}=K_{E} \cdot \dot{\varepsilon}^{n} \cdot \varepsilon_{b}{ }^{S H I}$ \\
& $\left(T \geq T_{g}+30^{\circ} \mathrm{C}\right)$ & \\
& $=\mathrm{a} \cdot M C^{-2.3}$ & \\
&
\end{tabular}

strain rate, $\varepsilon_{b}$ is biaxial strain, and $S H I$ is the strain hardening index.

Nevertheless, in practice, these equations may not be sufficient to effectively assess the state of the product. In the breadmaking industry, dough state is defined by a whole set of sensory criteria-stickiness, consistency, elasticity, and so on-that are evaluated by the baker, not measured instrumentally. In order to capture this domain expertise or know-how, a qualitative model has been developed and implemented as a Knowledge Base System (KBS). The KBS computes sensory criteria describing a wheat dough as a function of process parameters (input variables) like SME (Ndiaye, Della Valle, \& Roussel, 2009). This KBS can be used by professionals in order to simulate, for instance, the effect of ingredients and mixing parameters on dough consistency (Kansou, Chiron, Della Valle, Ndiaye, \& Roussel, 2014).

In cereal processing, the steps that follow mixing are expansion or fermentation. Here the cellular structure is created by gas production, and the volume increase is controlled by the elongational viscosity $\eta_{E}$, expressed in Table 1, before final setting by cooling or baking, respectively. At macroscopic level, dough porosity and extrudate radial expansion may be computed by phenomenological models involving $\eta_{E}$, derived from the classical simple bubble growth model:

$\frac{1}{R} \frac{d R}{d t} \approx \frac{P_{v}}{\eta_{E}}$

where $R$ is bubble radius and $P_{v}$ is internal gas pressure of the bubble. These models can compute the volume expansion and then porosity from rheological and process variables, as illustrated in Fig. 4, when coupled with models of mixing. The target product porosity, or density, can then be obtained from the right operation variables. Using X-ray microtomography (XRT) and image analysis, the cellular structure can be characterized by cell size and the average values for cell wall thickness, which defines its fineness and homogeneity. By ascertaining the bubble growth and coalescence mechanisms, we can link the structure at macroscopic and microscopic scales, and from there determine cellular fineness from macroscopic information (Kristiawan

(a)

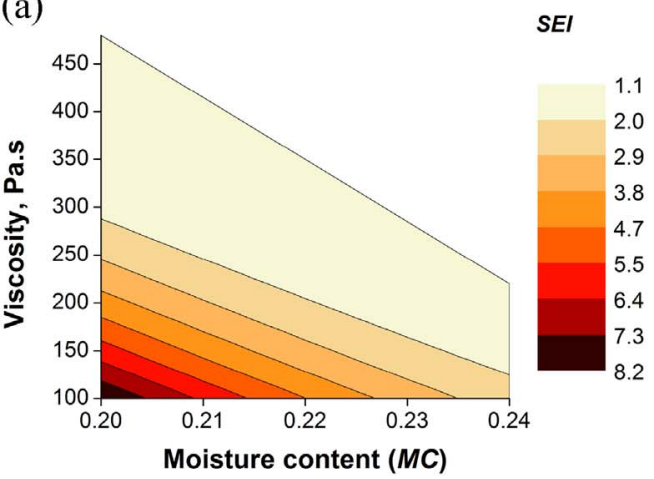

et al., 2016). Finally, using these structural features, mechanical properties can be computed by numerical modeling, and thus the texture of the cereal food foam can be assessed (Guessasma, Chaunier, Della Valle, \& Lourdin, 2011).

These basic models can be applied beyond the limits of the continuous mechanics approach. They underline the need to integrate scientific knowledge and know-how, but they also pave the way to the digital transition of processes by the assembly of models for the design of cereal products.

\section{Argumentation for decision support: example in the cereals chain}

Food chain analysis is a highly complex procedure since it relies on numerous criteria of various types: environmental, economical, functional, health-hygiene, and more. Quality objectives imply different stakeholders, whose goals may be divergent, which means decisionmaking raises arbitration issues. An argumentation-based approach to support decisionmaking in food chains is presented here in a case study concerning risk/benefit analysis within the wheat-to-bread chain. The case concerns controversy over the possible change in ash content of the flour used for a commonly used French bread. Several stakeholders in the chain are concerned, in particular the Ministry of Health through its recommendations in a national nutrition \& health program ('PNNS'), plus millers, bakers, and of course consumers.

\subsection{Information sources}

Information sources used in this study include, from most formal to least formal, scientific peer-reviewed articles, technical reports, scientific conferences and research project meetings, information published on official websites, and expert knowledge obtained through interviews. Details on the information sources used in the study can be found in Bourguet, Thomopoulos, Mugnier, and Abécassis (2013) and Bourguet (2010).

\subsection{Argumentation models}

Argumentation is a reasoning model based on the construction and evaluation of interacting arguments. Most of the existing models are grounded in the abstract argumentation framework proposed in Dung (1995), where an argumentation system is defined by a set of arguments $A$, and an attack relation between arguments $R$. Sets of arguments that 'make sense' together, called extensions, are then computed. Ensuing studies enriched Dung's model with complementary features, such as the consideration of preferences among arguments, expressing that some arguments may be stronger than others, the consideration of

(b)

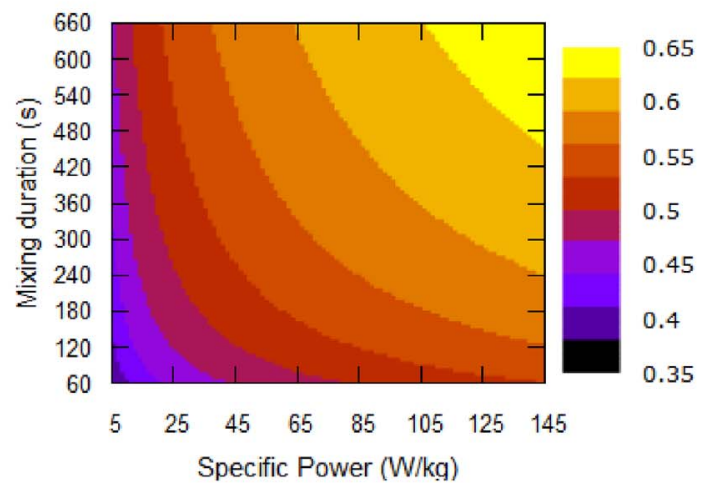

Fig. 4. Examples of results obtained by simulation of (a) starch melt radial expansion (SEI) and (b) dough porosity increase during fermentation using phenomenological models. (adapted from Kristiawan et al., 2015 and Kansou et al., 2013) 
contexts (see Bourguet, Amgoud, \& Thomopoulos, 2010 for a comparison of models), and the definition of logic-based structured argumentation systems (Modgil \& Prakken, 2013; Tamani et al., 2015; Thomopoulos, Croitoru, \& Tamani, 2015).

Classically, the argumentation process follows three main steps: 1 ) constructing arguments and counter-arguments, 2) evaluating the acceptability of the different arguments, and 3) concluding.

\subsection{Argument inventory and formalization}

In the considered policy decision, the PNNS recommends developing the consumption of breads made with more wholewheat flour, such as Type- 80 flour (containing $0.80 \mathrm{~g}$ of minerals per $100 \mathrm{~g}$ of flour on a dry basis) instead of the Type-65 flour currently used ( $0.65 \mathrm{~g}$ per $100 \mathrm{~g}$ ). The recommendations are mainly supported by nutritional arguments related to increasing fiber intake, and buttressed by economic arguments related to increasing the yield of raw material extraction (wheat). Two alternatives are highlighted: change common bread to Type-80 flour (denoted T80) or keep Type-65 flour (denoted T65). The PNNS arguments take into account different concerns (Nutrition, Technology, Economy) and pursue several goals (\%Fiber, \% Micronutrients, Process Skills, Costs). However, these arguments are hampered by strong reserves voiced by the wheat processing stakeholders concerned. For instance, professional bakers and millers are wary of the potential impacts on their core activities. The French milling profession is pushing for a reconsideration of the PNNS recommendations. A scientific report investigating nutritional impacts of Type- 80 flour was published and used as reference material by the profession. Table 2 lists some of the arguments put forward by the millers' trade, which supports the conservative option (Action $=\mathrm{T} 65$ ) or a reconsideration of the recommendation (D for "debranning", $\mathrm{O}$ for "organic").

\subsection{Argumentation-based decision model}

The proposed decision framework takes into account a set of arguments $A$, a set of concerns $C$, a set of actions $D$ (for "Decisions"), and a set of (ordered) goals $G$. It is defined as a tuple $(A, C, D, G, \geq, \alpha, \gamma)$ where:

- $C=\left\{c_{1}, \ldots, c_{n}\right\}$ is a set of concerns;

- $A$ is a set of arguments, divided into subsets $A_{1}, \ldots, A_{n}$ of arguments that are expressed in the concerns $c_{1}, \ldots, c_{n}$ respectively;

- $D$ is a set of mutually exclusive decision-actions;

- $G$ is a set of goals;

- $\geq=\left\{\geq_{1}, \ldots, \geq_{n}\right\}$ is a set of (preorder) relations on G. Each $\geq_{i}$ defines a preference ordering of the goals $G$, that applies for the concern $c_{i}$;

- $\alpha$ is a function $\mathrm{A} \rightarrow \mathrm{D}$ that associates each argument with an action;

- $\gamma$ is a function $A \rightarrow G$ that associates each argument with a goal.

Based on this definition, the attack relation $\mathrm{R}$ is then computed: for a given concern, an argument $a$ attacks an argument $b$ if and only if their actions are mutually exclusive and the goal of $b$ is not preferred to the goal of $a$. Formally, given a decision framework $(A, C, D, G, \geq, \alpha, \gamma$ ), $R=\left\{R_{1}, \ldots, R_{n}\right\}$ is a set of attack relations, defined on $A_{1}, \ldots, A_{n}$, respectively, such that:

$\forall(a, b) \in A_{i}{ }^{2},\left[(a, b) \in R_{i}\right] \Leftrightarrow\left[\alpha(a) \neq \alpha(b)\right.$ and $\left.(\gamma(b), \gamma(a)) \notin>{ }_{i}\right]$.

For each concern, arguments and attacks are now defined and the resolution can be obtained as in a classical Dung's system (Dung, 1995) by computing the extensions.

\subsection{Case-study output: an illustration}

The following steps were successively performed:

1. List all arguments, with their associated stakeholders, concerns, goals and actions.

2. Define the preference relation for each concern, i.e. a prioritization between goals.

3. Deduce the attack relation between arguments.

4. Compute the resolution, which leads to recommending one or several actions.

We illustrate the results through the health-hygiene concern. Several cases of preferences and the corresponding output recommendations are summarized in Table 3. The two recommendations "debranning wheat flour" (T80 \& D) and "organic bread" (T80 \& O) can finally be aggregated into a single recommendation "debranning and organic bread" (T80 \& D.O.), since both actions are compatible.

This output would be counterbalanced if other concerns were considered. For instance, in the economic concern, none of these actions is recommended when reducing costs and increasing benefits are preferred.

\section{Eco-design of the production process for concentrated microorganism (starters)}

Lactic acid bacteria are biological agents widely used in domains ranging from fermented food (e.g. yoghurt, cheese) to medicine (e.g. probiotics) to non-food domains (e.g. active molecule production). The market for concentrated microorganisms (starters) is showing steady growth, and it relies on the production of stabilized and ready-to-use products. However, many strains exhibiting interesting functionalities cannot be suitably preserved today, so the preservation processes need to be revisited to improve their performances. The production of starters is a multi-stage process that involves a sequence of several unit operations: fermentation, cooling, concentration, formulation, freezing or freeze-drying, and storage (often at negative temperatures) of the frozen or freeze-dried microorganisms.

The food process engineering approach usually focuses on a single unit operation of the process/system for analysis, simulation and/or control, with product quality and/or efficiency targets, as illustrated in Fig. 5. However, there are strong connections between the unit operations of this multi-stage process, and the 'standard' approach fails to

Table 2

Part of millers' argumentation.

\begin{tabular}{|c|c|c|c|c|c|}
\hline & Stakeholder & Reason & Action & Concern(s) & Goal(s) \\
\hline 1 & Millers & "Raising the flour extraction rate causes an increase in flour contaminants." & T65 & Sanitary & $\begin{array}{l}\downarrow \text { Mycotoxins } \\
\downarrow \text { Pesticide Residues }\end{array}$ \\
\hline 2 & Millers & "Wheat pretreatments (such as debranning) could decrease mycotoxins." & T80 \& D. & $\begin{array}{l}\text { Sanitary } \\
\text { Technology }\end{array}$ & $\begin{array}{l}\downarrow \text { Mycotoxins } \\
\uparrow \text { Process Skills }\end{array}$ \\
\hline 3 & Millers & "Wheat pretreatments increase process costs." & T65 & Economy & $\downarrow$ Costs \\
\hline 4 & Millers & "Making organic bread allows to avoid pesticide residues." & $\mathrm{T} 80 \& \mathrm{O}$ & $\begin{array}{l}\text { Sanitary } \\
\text { Economy }\end{array}$ & $\begin{array}{l}\downarrow \text { Pesticide Residues } \\
\uparrow \text { Segmented Supply }\end{array}$ \\
\hline 5 & Millers & "Raising flour extraction rate causes a rise in phytic acid." & T65 & Nutrition & $\downarrow$ Phytic Acid \\
\hline
\end{tabular}


Table 3

Different preference scenarios and associated outputs in the health-hygiene concern.

\begin{tabular}{ll}
\hline Preferences & Recommended action(s) \\
\hline$\downarrow$ Mycotoxins $\geq \downarrow$ Pesticide Residues & T65, T80 \& D. \\
$\downarrow$ Pesticide Residues $\geq \downarrow$ Mycotoxins & T80 \& O. \\
$\downarrow$ Mycotoxins $\approx \downarrow$ Pesticide Residues & T65, T80 \& D., T80 \& O. \\
\hline
\end{tabular}

account for them. For instance, it is possible to pre-adapt microorganisms during the fermentation step, allowing them to activate their defense mechanisms (via the regulation of the expression level of specific genes) and, consequently, to better resist stresses they will face later in the process (temperature, dehydration, oxidation, etc.). Such connections can provide opportunities for process/system innovation, but there is a lack of tools that would make systemic approaches easily implementable in food process engineering.

Furthermore, at the unit operations level, heating, cooling and refrigeration consume approximately $45 \%$ of the total energy used in the food, drink and milk sectors (European Commission, 2006). Moreover, the cold chain was reported to need environmental improvements (James \& James, 2010) due to its high footprint in terms of energy consumption, air pollutants and noise (European Commission, 2006). This makes reducing the environmental impact of this kind of starter production system a relevant challenge that should be considered in a systemic approach designed to reach high eco-efficiency levels (Fig. 5).

\subsection{Environmental issues}

First, the lactic acid bacteria starters production system was analyzed using life-cycle assessment (LCA). This systemic approach provided a quantification of the global environmental impacts (Fig. 5) and served to identify hotspots and compare different existing scenarios. The LCA was performed on the basis of data collected at lab scale and completed with databases. Since freezing, freeze-drying and storage can damage bacterial cells, the impact scores were weighted by bacterial quality, i.e. their final physiological state, to obtain meaningful comparisons (Pénicaud, Monclus, Perret, Passot, \& Fonseca, 2016). Fermentation, freeze-drying, and frozen storage were evidenced as the hotspots of the environmental impact of the system.

Furthermore, the system could be revised according to the final product's time in storage, especially with the choice of stabilization technology to limit the storage-phase impact. Freeze-drying appeared more eco-friendly than freezing for storage longer than two months, as the high environmental impact of storage at the very low temperatures required for frozen products $\left(-40^{\circ} \mathrm{C}\right.$ vs $-18{ }^{\circ} \mathrm{C}$ for freeze-dried bacteria) compensated for the energy required for freeze-drying. Increasing the storage temperature of freeze-dried bacteria (ambient temperature instead of $-18^{\circ} \mathrm{C}$ ) was also investigated, but the strong losses of bacterial quality occurring at ambient temperature implied producing higher quantities of stabilized bacteria, thus cancelling out the possible environmental benefit of increasing storage temperature.

\subsection{Process engineering: from analysis to smart control of the freeze-drying process}

Freeze-drying was identified as a hotspot of the production chain due to its energy consumption, and was thus further investigated in depth and detail through energy balances. Energy sensors were placed to monitor the main components of a pilot freeze-dryer, i.e. compressors, heating resistance, vacuum pump and shelf fluid circulation pump. Freeze-drying experiments were carried out on different amounts of product and applying various shelf temperature profiles during the process. Duration of the process emerged as the main parameter influencing energy consumption (Pénicaud et al., 2014).

A previously developed freeze-drying optimization tool (Trelea, Passot, Fonseca, \& Marin, 2007) appeared an immensely useful solution for minimizing both the duration of the process and the decline in quality of the freeze-dried bacteria. Simulations were performed in order to define an optimal process minimizing the energy consumptions. This "eco-friendly" process allowed a 16\% energy saving while preserving bacterial quality in the freeze-drying step (Pénicaud et al., 2014).

Further work will consist in developing an on-line and real-time optimization tool that includes energy consumption. This will improve previous work on the optimization and smart control of both product quality and freeze-drying process duration (Antelo, Passot, Fonseca, Trelea, \& Alonso, 2012).

\subsection{Towards eco-design in a systemic approach: contribution of knowledge integration}

Although process engineering - and especially smart control-is a powerful approach for decreasing environmental impact while considering product quality, better eco-efficiency could be obtained by extending the eco-design from unit operation level to production-chain level (Fig. 5). Furthermore, in order to account for the specificities of

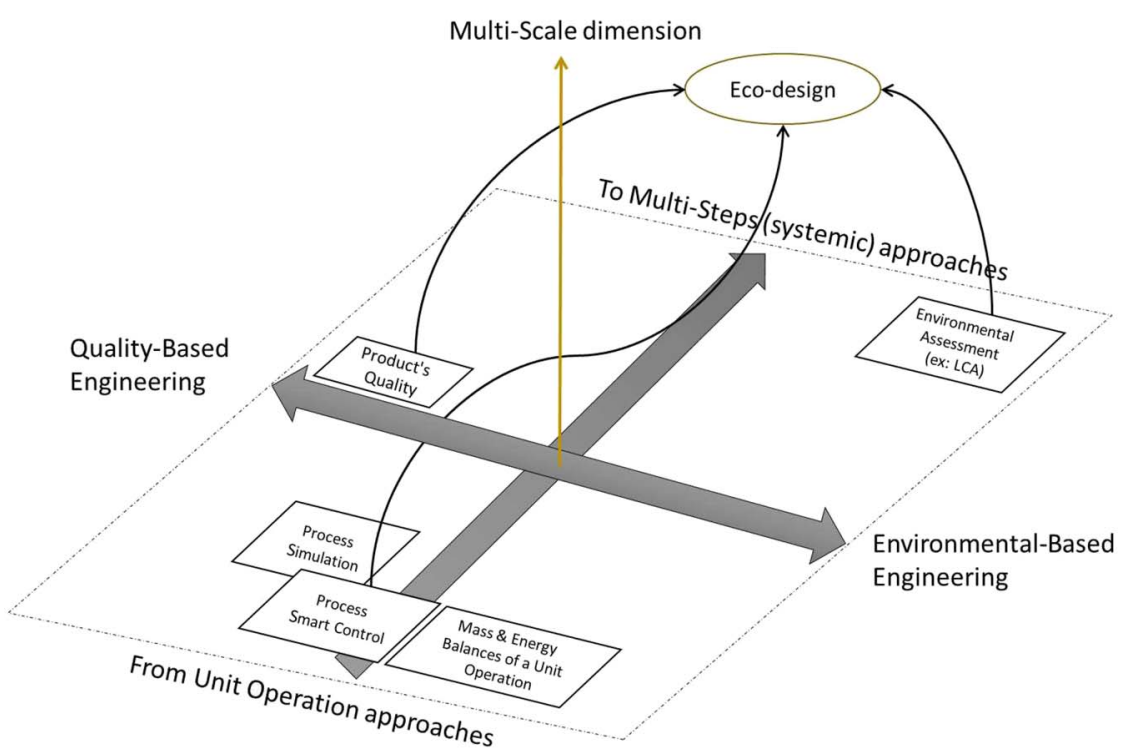

Fig. 5. Eco-design requires a shift from unit operation-focused approaches to systemic approaches in food and bioprocess engineering, by taking into account both product quality and environmental impacts, defined at different scale levels of the system. 
Table 4

Synthesis and feedback.

\begin{tabular}{|c|c|c|c|}
\hline Issue & Method & Results & Feedback \\
\hline \multicolumn{4}{|c|}{ Section 2. Objectives: capitalize data and knowledge/structure a shared vocabulary and domain knowledge in an ontology } \\
\hline $\begin{array}{l}\text { Modeling of the production kinetics } \\
\text { of } \mathrm{CO}_{2} \text {, fermentative aromas and } \\
\text { energy requirements }\end{array}$ & $\begin{array}{l}\text { Ordinary differential equations coupled to } \\
\text { nonlinear regression methods }\end{array}$ & $\begin{array}{l}\text { Very accurate predictions, mean difference } \\
\text { between experimental and estimated } \\
\text { values below } 10 \%\end{array}$ & $\begin{array}{l}\text { 1/ Possibility to model, for the first time, } \\
\text { the kinetics of production of } 5 \text { fermentative } \\
\text { aromas } \\
2 \text { / Development of innovative strategies to } \\
\text { control the synthesis of these volatile } \\
\text { compounds }\end{array}$ \\
\hline $\begin{array}{l}\text { Implementation of a knowledge } \\
\text { management system of } \\
\text { enological fermentations }\end{array}$ & $\begin{array}{l}\text { Database system, approaches based on } \\
\text { ontologies }\end{array}$ & $\begin{array}{l}\text { Use of professional know-how and "smart" } \\
\text { management of all fermentation-related } \\
\text { faults, operations and decisions }\end{array}$ & $\begin{array}{l}\text { 1/ Improvement of data quality and } \\
\text { understanding } \\
2 \text { / Possibility to apply the same strategy to } \\
\text { other case studies }\end{array}$ \\
\hline
\end{tabular}

Section 3. Objectives: capitalize data and knowledge/support multi-criteria decision-making

How do we address decisions in the Use some mathematical models for food field of food packaging when engineering to simplify the system while several physical mechanisms are keeping most of the representativeness to underlying and overlapping? compute fairly simple technical outputs that will help inform decision-making

Several tools coupling mass transfer mathematical models and food degradation reaction models (respiration, microbial growth, oxidation, etc.), e.g. Tailorpack, Map'Opt tools

How do we address decisions when several sometimes contradictory criteria are involved?

Use methodologies borrowed from flexible querying: technical outputs of the mathematical models for food engineering are used to build the query

How do we propose efficient, versatile decision-making tools?

Capitalize relevant data in a dedicated data warehouse. Use text mining tools to enhance efficiency of capitalization

Section 4. Objectives: capitalize data and knowledge

Cereal foams design involves complex processes that cannot be fully tackled by mechanical modeling.

Integration of scientific and expert knowledge to build basic, qualitative and phenomenological models involving rheological properties.

A first prototype decision support too (DST) using flexible querying modules is available, based on four different criteria

More than 1538 experimental measures including 38 Relation concepts defining types of measurement, e.g. permeabilities, diffusivities, described by 55 quantities associated with 159 units of measure including conversion factors

Tools that allow professionals to simulate with process variables and viscosity. cereal foam porosity and cellular structure

Section 5. Objectives: formalize viewpoints and contradictions in a debate/support multi-criteria decision-making Representation and resolution of Argumentation-based decisionmaking: contradictory viewpoints:

- which formal methods to represent and resolve a debate? Quantification of the environmental Life cycle assessment issues associated to the bacterial starters production system (can be completely generalized)

Reduction of the energy consumption of the freezedrying process (can be completely generalized)

On-line reduction of freeze-dryingprocess energy consumption (can be completely generalized)

System-level eco-design of the bacterial starters production system (can be completely generalized)
- A method borrowed from artificial intelligence

- So far mainly applied in the judicial sector

- Well-suited for the formal representation and treatment of initially "unformal" arguments

- - Innovative in food chains

An argumentation model providing recommended decisions in the case of multiple concerns, depending on the chosen priorities.

e.g. various possible prioritizations in health-hygiene/nutritional/economic concerns, etc.

y/support multi-criteria decision-making * Identification of hotspots (major impact steps): fermentation, freeze-drying and storage

* Trade-off to find between energy needed for process, energy needed for cold storage, and quality of final product

A $16 \%$ reduction of energy consumption

Smart process control

Not yet implemented

Knowledge integration: Ontology
Ontology $[\mathrm{MS}]^{2} \mathrm{O}$ : able to integrate data from products submitted to transformation processes. Data can come from different scale levels of investigation: from gene to environmental impacts (e.g. global warming).

Validated semi-mechanistic models. Approach that is generalizable to many other applications. Several tools are in the pipeline in the same field of application to take into account the diversity of food products and degradation reactions To extend the DST and the number of criteria considered, research is still needed to connect models coming from different disciplinary fields (for instance LCA outputs and mass transfer models)

Efficient data capitalization needs to motivate people to get involved in this capitalization

Use of such tools to feed models for predicting texture and for learning processes and cereal foods rheology.

\footnotetext{
- Relevant way to help stakeholders elici and formalize arguments, which would make them more involved in the decision process and facilitate interactions between them.

- Promising approach for well-balanced decisions, considering all aspects of a problem.
}

Identification of eco-design options. Efficient approach for assessment, but ecodesign still has to be implemented in a second step.

Approach is efficient but unit-operationbased-the whole production system cannot be simulated.

Approach is efficient but unit-operationbased-the whole production system cannot be simulated.

Data are integrated, but the tool allowing querying of the data to emerge eco-design options has not yet been implemented.

bio-based products and provide a complete and representative analysis of the system, a multi-scale approach "from gene up to process" should be implemented. The main events taking place during the process involve mass and heat transfers associated to the applied unit operations, and will have big consequences on both product quality (due to active or passive cell responses) and environmental impacts. Active cell responses result from the expression of the cell's genes, which leads to variable concentrations of proteins, lipids and sugars at molecular level and to different organizations at cellular level. However, a target functionality expresses itself at the cellular level whereas it can generally only be evaluated at population level. As the multi-scales approach is essential to R \& D for bio-based products, it should thus be 
integrated together with the environmental assessment to study the whole system.

Finally, an innovative eco-design approach may arise from multicriteria indicators associating the function to be preserved, the process constraints, and the environmental impact. To answer this challenge, our lab books contain huge amounts of data on (i) microorganisms at different scales (from microbial cell components to the target functionality at population level) and at different stages of the production process, (ii) unit operations (e.g. technology used, working conditions and recipes), (iii) the environmental impacts of the system, as computed using LCA for instance. The modeling and exploitation of available data represent important bottlenecks due to their heterogeneity, multi-scale dimensions, sparseness, and time-course evolution through the different unit operations of the production process. Nevertheless, capitalizing this data at enriching it with bibliographic data is critical for sustainable process development.

To this end, an ontology, called [MS $]^{2} \mathrm{O}$ for Multi-Scales and MultiSteps Ontology, was defined to integrate the knowledge and data available on the system (Dibie, Dervaux, Doriot, Ibanescu, \& Pénicaud, 2016). A database, called BAGATEL, was built according to the $[M S]^{2} \mathrm{O}$ vocabulary in order to integrate and store the data and therefore make it available for further querying. $[\mathrm{MS}]^{2} \mathrm{O}$ aims to play a key role as the representation layer of the querying system. The ongoing implementation of a user-friendly BAGATEL-[MS $]^{2} \mathrm{O}$ interface will enable to compare different micro-organism production scenarios and find improvements by taking into account different criteria, typically product quality, process efficiency and environmental impacts.

Furthermore, $[\mathrm{MS}]^{2} \mathrm{O}$ has been re-engineered to make it applicable to other domains, as long as they are devoted to transformation processes, but independently of the product submitted to the transformation. The new $\mathrm{PO}^{2}$ ontology (Process and Observation Ontology) has been successfully applied to dairy gels (Ibanescu, Dibie, Dervaux, Guichard, \& Raad, 2016). These generic knowledge integration approaches are anticipated to drive the development of bio-based products according to nutritional and/or functional properties while increasing efficiency within a wider eco-design approach.

\section{Conclusion: summary and feedback}

As a synthesis, we propose a summary of the objectives, issues, methods and results presented in the paper, together with feedback, in Table 4. Further structuration of the international community working on mathematical and computer science research approaches to food systems should hopefully complete this matrix, which could evolve into a methodological tool to better identify which method(s) best fit which issue(s). The "FoodMC" COST Action initiative at the European level (www.inra.fr/foodmc) provides a first attempt in this way.

\section{Acknowledgments}

The authors thank Juliette Dibie, Stéphane Dervaux and Liliana Ibanescu for designing and developing the $[\mathrm{MS}]^{2} \mathrm{O}$ and $\mathrm{PO}^{2}$ ontologies, and Hervé Guillemin and Bruno Perret for developing the BAGATEL database and hosting it at the INRA CEPIA division's PLASTIC platform.

\section{References}

Angellier-Coussy, H., Guillard, V., Guillaume, C., \& Gontard, N. (2013). Role of packaging in the smorgasbord of action for sustainable food consumption. Agro Food Industries, 23(4), 15-19.

Antelo, L. T., Passot, S., Fonseca, F., Trelea, I. C., \& Alonso, A. A. (2012). Toward optimal operation conditions of freeze-drying processes via a multilevel approach. Drying Technology, 30(13), 1432-1448.

Bacigalupi, C., Lemaistre, M. H., Peyron, S., Guillard, V., \& Chalier, P. (2013). Changes in nutritional and sensory properties of orange juice packed in PET bottles: An experimental and modelling approach. Food Chemistry, 141, 3827-3836.

Barron, C., Della Valle, G., Colonna, P., \& Vergnes, B. (2002). Energy balance of low hydrated starches transition under shear. Journal of Food Science, 67, 1426-1437.
Bourguet, J.-R. (2010). Contribution aux méthodes d'argumentation pour la prise de décision. Application à l'arbitrage au sein de la filière céréalière (PhD Thesis)Montpellier, France: Université Montpellier II.

Bourguet, J.-R., Amgoud, L., \& Thomopoulos, R. (2010). Towards a unified model of preference-based argumentation. Proceedings of international symposium of Foundations of Information and Knowledge Systems (FoIKS) (pp. 326-344). .

Bourguet, J.-R., Thomopoulos, R., Mugnier, M.-L., \& Abécassis, J. (2013). An artificial intelligence-based approach to deal with argumentation applied to food quality and public health policy. Expert Systems with Applications, 40, 4539-4546.

Buche, P., Dervaux, S., Dibie-Barthélemy, J., Soler, L., Ibanescu, L., \& Touhami, R. (2013). Intégration de données hétérogènes et imprécises guidée par une ressource terminoontologique, Application au domaine des sciences du vivant. Revue d'Intelligence Artificielle, 27, 515-537.

Buche, P., Destercke, S., Guillard, V., Haemmerlé, O., \& Thomopoulos, R. (2012). Flexible bipolar querying of uncertain data using an ontology. In J. Kacprzyk (Ed.). Studies in computational intelligence. Springer.

Buche, P., Dibie, J., Ibanescu, M., \& Soler, L. (2013). Fuzzy web data tables integration guided by an ontological and terminological resource. IEEE Transactions on Knowledge and Data Engineering, 25(4), 805-819.

Cagnon, T., Méry, A., Chalier, P., Guillaume, C., \& Gontard, N. (2013). Fresh food packaging design: A requirement driven approach applied to strawberries and agrobased materials. Innovative Food Science \& Emerging Technologies, 20, 288-298. http:// dx.doi.org/10.1016/j.ifset.2013.05.009.

Chaix, E., Broyart, B., Couvert, O., Guillaume, C., Gontard, N., \& Guillard, V. (2015). Mechanistic model coupling gas exchange dynamics and Listeria monocytogenes growth in modified atmosphere packaging of non respiring food. Food Microbiology, 51, 192-205. http://dx.doi.org/10.1016/j.fm.2015.05.017.

Chaix, E., Couvert, O., Guillaume, C., Gontard, N., \& Guillard, V. (2015). Predictive microbiology coupled with gas $(\mathrm{O} 2 / \mathrm{CO} 2)$ transfer in food/packaging systems: How to develop an efficient decision support tool for food packaging. Comprehensive Reviews in Food Science and Food Safety, 14, 1-21.

Colombie, S., Malherbe, S., \& Sablayrolles, J. M. (2007). Modeling of heat transfer in tanks during wine-making fermentation. Food Control, 18, 953-960. http://dx.doi. org $/ 10.1016 / \mathrm{j}$.foodcont.2006.05.016.

Della Valle, G., Barrès, C., Plewa, J., Tayeb, J., \& Vergnes, B. (1993). Computer simulation of starchy products transformation by twin screw extrusion. Journal of Food Engineering, 19, 1-31.

Della Valle, G., Chiron, H., Cicerelli, L., Kansou, K., Katina, K., Ndiaye, A., ... Poutanen, K. (2014). Basic knowledge models for the design of bread texture. Trends in Food Science and Technology, 36, 5-14.

Destercke, S., Buche, P., \& Guillard, V. (2011). A flexible bipolar querying approach with imprecise data and guaranteed results. Fuzzy Sets and Systems, 169(1), 51-64.

Dibie, J., Dervaux, S., Doriot, E., Ibanescu, L., \& Pénicaud, C. (2016). [MS]²O - A multiscale and multi-step ontology for transformation processes: Application to microorganisms. Proceedings of ICCS' 2016 (International Conference on Conceptual Structures), LNCS 9717 (pp. 163-176). Springer.

Dung, P. M. (1995). On the acceptability of arguments and its fundamental role in nonmonotonic reasoning, logic programming and n-person games. Artificial Intelligence Journal, 77, 321-357.

European Commission, J. R. C (2006). Reference document on best available techniques in the food, drink and milk industry. http://oldaaa.gamta.lt/aaa/Tipk/tipk/1_bref/ 12.pdf.

Floros, J. D., \& Matsos, K. I. (2005). Introduction to modified atmosphere packaging. In J. H. H. B. T.-I. in F. Packaging (Ed.). Innovations in food packaging (pp. 159-172). New York, USA: Elsevier Academic Press.

Francis, I. L., \& Newton, J. L. (2005). Determining wine aroma from compositional data. Australian Journal of Grape and Wine Research, 11, 114-126. http://dx.doi.org/10. 1111/j.1755-0238.2005.tb00283.x.

Goelzer, A., Charnomordic, B., Colombié, S., Fromion, V., \& Sablayrolles, J. M. (2009). Simulation and optimization software for alcoholic fermentation in winemaking conditions. Food Control, 20, 635-642. http://dx.doi.org/10.1016/j.foodcont.2008. 09.016.

Guessasma, S., Chaunier, L., Della Valle, G., \& Lourdin, D. (2011). Mechanical modelling of cereal solid foods. Trends in Food Science \& Technology, 22, 142-153.

Guillard, V., Buche, P., Destercke, S., Tamani, N., Croitoru, M., Menut, L., ... Gontard, N. (2015). A decision support system to design modified atmosphere packaging for fresh produce based on a bipolar flexible querying approach. Computers and Electronics in Agriculture, 111, 131-139. http://dx.doi.org/10.1016/j.compag.2014.12.010.

Guillard, V., Buche, P., Dibie, J., Dervaux, S., Acerbi, F., Chaix, E., ... Guillaume, C. (2016). CO2 and O2 solubility and diffusivity data in food products stored in data warehouse structured by ontology. Data in Brief, 7, 1556-1559. http://dx.doi.org/10. 1016/j.dib.2016.04.044.

Guillard, V., Couvert, O., Stahl, V., Hanin, A., Denis, C., Huchet, V., ... Thuault, D. (2016). Validation of a predictive model coupling gas transfer and microbial growth in fresh food packed under modified atmosphere. Food Microbiology, 58, 43-55. http://dx.doi. org/10.1016/j.fm.2016.03.011.

Guillard, V., Guillaume, C., \& Destercke, S. (2012). Parameter uncertainties and error propagation in modified atmosphere packaging modelling. Postharvest Biology and Technology, 67, 154-166. http://dx.doi.org/10.1016/j.postharvbio.2011.12.014.

Guillaume, C., Guillard, V., \& Gontard, N. (2010). Modified atmosphere packaging of fruits andvegetables: Modeling approach. In O. Martin-Belloso, \& S. Soliva-Fortuny (Eds.). Advances in fresh-cut fruits and vegetables processing (pp. 255-284). Boca Raton: CRC Press.

Ibanescu, L., Dibie, J., Dervaux, S., Guichard, E., \& Raad, J. (2016). PO ${ }^{2}$ - A process and observation ontology in food science. Application to dairy gels. Proceeding of MTSR 2016. 
James, S. J., \& James, C. (2010). The food cold-chain and climate change. Food Research International, 43(7), 1944-1956.

Kansou, K., Chiron, H., Della Valle, G., Ndiaye, A., \& Roussel, P. (2014). Predicting the quality of wheat flour dough after mixing by modelling expert's know-how. Food Research International, 64, 772-782.

Kansou, K., Chiron, H., Della Valle, G., Ndiaye, A., Roussel, P., \& Shehzad, A. (2013). Modelling wheat flour dough proofing behaviour: Effects of mixing conditions on porosity and stability. Food and Bioprocess Technology, 6, 2150-2164.

Kristiawan, M., Chaunier, L., Della Valle, G., Ndiaye, A., \& Vergnes, B. (2016). Modeling of starchy melts expansion by extrusion. Trends in Food Science and Technology, 48 $13-26$.

Kristiawan, M., Della Valle, G., Kansou, K., Ndiaye, A., Vergnes, B., \& David, C. (2015). A phenomenological model of starch expansion by extrusion. Rhéologie, 27, 24-33.

Malherbe, S., Fromion, V., Hilgert, N., \& Sablayrolles, J. M. (2004). Modeling the effects of assimilable nitrogen and temperature on fermentation kinetics in enological conditions. Biotechnology and Bioengineering, 86, 261-272. http://dx.doi.org/10.1002/ bit. 20075.

Modgil, S., \& Prakken, H. (2013). A general account of argumentation with preferences. Artificial Intelligence, 195, 361-397.

Morakul, S., Mouret, J. R., Nicolle, P., Trelea, I. C., Sablayrolles, J. M., \& Athes, V. (2011). Modelling of the gas-liquid partitioning of aroma compounds during wine alcoholic fermentation and prediction of aroma losses. Process Biochemistry, 46, 1125-1131. http://dx.doi.org/10.1016/j.procbio.2011.01.034.

Mouret, J. R., Farines, V., Sablayrolles, J. M., \& Trelea, I. C. (2015). Prediction of the production kinetics of the main fermentative aromas in winemaking fermentations. Biochemical Engineering Journal, 103, 211-218. http://dx.doi.org/10.1016/j.bej 2015.07.017.

Mouret, J. R., Morakul, S., Nicolle, P., Athes, V., \& Sablayrolles, J. M. (2012). Gas-liquid transfer of aroma compounds during winemaking fermentations. LWT- Food Science and Technology, 49, 238-244. http://dx.doi.org/10.1016/j.lwt.2012.04.031.

Muljarto, A. R., Salmon, J. M., Neveu, P., Charnomordic, B., \& Buche, P. (2014). Ontology-based model for food transformation processes - Application to winemaking. In S. Closs, R. Studer, E. Garoufallou, \& M.-A. Sicilia (Vol. Eds.), Communications in computer and information science: . 478. Metadata and Semantics Research SE-30 (pp. 329-343). Springer International Publishing. http://dx.doi.org/
10.1007/978-3-319-13674-5 30.

Ndiaye, A., Della Valle, G., \& Roussel, P. (2009). Qualitative modelling of a multi-step process: The case of French breadmaking. Expert Systems with Applications, 39, 1020-1038.

Neveu, P., Rossard, V., Tireau, A., Aguera, E., Perez, M., Picou, C., \& Sablayrolles, J. M. (2012). Software for data and knowledge management in winemaking fermentations. SciTePress - Science and and Technology Publications369-372. http://dx.doi.org/10. 5220/0004138803690372.

Pénicaud, C., Broyart, B., Peyron, S., Gontard, N., \& Guillard, V. (2011). Mechanistic model to couple oxygen transfer with ascorbic acid oxidation kinetics in model solid food. Journal of Food Engineering, 104(1), 96-104.

Pénicaud, C., Monclus, V., Perret, B., Passot, S., \& Fonseca, F. (2016). Production of stabilized lactic acid bacteria viewed from a life cycle assessment perspective. Presented at the LCA Food 2016, Dublin, Ireland.

Pénicaud, C., Trelea, I. C., Perret, B., Fonseca, F., Athès, V., \& Passot, S. (2014). Insights into freeze-drying energy consumptions for an environmentally-reasoned process control. 4th international congress on green process engineering. Sevilla - Spain.

Shehzad, A., Chiron, H., Della Valle, G., Lamrini, B., \& Lourdin, D. (2012). Rheological and energetical approaches of wheat flour dough mixing. Journal of Food Engineering, 110, 60-70.

Swiegers, J. H., Bartowsky, E. J., Henschke, P. A., \& Pretorius, I. S. (2005). Yeast and bacterial modulation of wine aroma and flavour. Australian Journal of Grape and Wine Research, 11, 139-173.

Tamani, N., Mosse, P., Croitoru, M., Buche, P., Guillard, V., Guillaume, C., \& Gontard, N. (2015). An argumentation system for eco-efficient packaging material selection. Computers and Electronics in Agriculture, 113, 174-192.

Thomopoulos, R., Croitoru, M., \& Tamani, N. (2015). Decision support for agri-food chains: A reverse engineering argumentation-based approach. Ecological Informatics, 26(2), 182-191.

Trelea, I. C., Passot, S., Fonseca, F., \& Marin, M. (2007). An interactive tool for the optimization of freeze-drying cycles based on quality criteria. Drying Technology, 25(4-6), 741-751.

Turbin-Orger, A., Shehzad, A., Chaunier, L., Chiron, H., \& Della Valle, G. (2016). Elongational properties and proofing behaviour of wheat flour dough. Journal of Food Engineering, 168, 129-136. 